\title{
An economic analysis of milk production in Haryana
}

\author{
Soumya Mohapatra ${ }^{1}$, Sendhil R ${ }^{2}$, Ajmer Singh ${ }^{1}$, A K Dixit ${ }^{1}$, R Malhotra $^{1}$ and K Ponnusamy ${ }^{3}$
}

Received: 18 July 2020 / Accepted: 12 November 2020 / Published online: 07 June 2021

(C) Indian Dairy Association (India) 2021

\begin{abstract}
Dairying is an important supplementary enterprise enhancing the livelihood of farmers and hence analyzing its profitability as well as identification of production constraints paves way for policy implications. An attempt was made to determine the costs, returns and constraints involved in milk production at Karnal and Jind districts of Haryana state during 2019-20. Primary data was collected from 120 milk producing households and was subjected to tabular analysis and Garrett's ranking technique. The overall net maintenance cost per animal per day was highest in the case of crossbred cow, followed by buffalo and indigenous cow. The overall cost of milk production was highest for buffalo (Rs. 40.35/litre), followed by crossbred ( 32.48/litre) and indigenous cow (Rs. 31.88/litre). A major portion in the total variable cost was contributed by the feed and fodder, followed by labour. Net return realized per litre of milk was positive across animal categories, but it was highest in the case of crossbred cow owing to higher productivity as compared to buffalo and indigenous cow. Distant location of artificial insemination centres and high price of concentrates were identified as the major production constraints faced by the farmers. The study advocates for adoption of better scientific breeding and management practices, mobile services for quality semen delivery as well as providing feeds at subsidized price channelizing through Farmer Producer Organizations (FPOs).
\end{abstract}

${ }^{1}$ Division of Dairy Economics, Statistics and Management, ICAR-

National Dairy Research Institute, Karnal-132 001, Haryana, India ${ }^{2}$ ICAR-Indian Institute of Wheat and Barley Research, Karnal-132 001, Haryana, India

${ }^{3}$ Department of Dairy Extension, ICAR-National Dairy Research Institute, Karnal-132 001, Haryana, India

Soumya Mohapatra $(\bowtie)$

${ }^{1}$ Division of Dairy Economics, Statistics and Management, ICAR-

National Dairy Research Institute, Karnal-132 001, Haryana, India Email: soumyaasubhashree@gmail.com
Keywords: Cost and returns, Capital recovery cost, Garrett ranking, Standard animal units

\section{Introduction}

Indian agriculture is predominantly a crop-livestock based production system and 70 per cent of the population is directly or indirectly engaged in agriculture. Due to pronounced adverse influence of vagaries of climate on crop production, dairy sector has been emerging as a stable source of livelihood and witnessing rapid strides in the recent past. Post launching of Operation Flood in 1970 and other dairy development programs, India emerged as the largest producer and consumer of dairy products in the world. Hence, dairy sector acts as a complementary enterprise to farming sector by providing employment as well as a stable source of income and nutritional requirement of family.Currently, the share of agriculture \& allied sector in 'Gross Value Addition' (GVA) is 17.2 per cent, out of which livestock sector alone contributes 4.9 per cent to GVA (National Accounts Statistics, 2019-20).India's agrarian economy has experienced most significant changes over past three-and-half decades due to the extremely impressive performance of dairy sector and continuously rising contribution of livestock sector in the agricultural gross domestic product. The share of livestock in agricultural gross domestic product has risen from 17 percent to 25.6 per cent between 1970 and 2019 (DAHD\&F, 2018-19). India has retained the status of highest milk producer in the world, annual milk production being 187.7 million tonnes, with a per capita availability of 374 gram/day (NDDB, 2018-19). The annual growth rate in milk production has been estimated around 6 per cent and India holds a share of around 19 per cent in global milk production (DAHD\&F, 201819). Milk is the ultimate output having economic significance which brings returns to the milk producers. Hence, estimation of the cost and returns of milk production acts as an important economic indicator for assessing the level of profit of dairy enterprise at the producers' level. The objective of the present study is to analyze the costs and returns of milk production across herd size and compare among the breeds viz., indigenous \&crossbred cows and buffaloes to know the relative profitability besides analyzing the break-even output (BEO). The analysis of various constraints faced by the dairy farmers can provide useful 
insights to policy makers for prioritizing the research and/or development agenda for dairy sector.

\section{Materials and Methods}

\section{Selection of study area}

Haryana possesses 2.5 per cent of country's total bovine population with growing annual milk production from 66.61 lakh tonnes in 2011-12 to 83.81 lakh tonnes in 2018-19 (Department of Animal Husbandry and Fishery, 2018-19). Haryana is among the top ten milk producing states in India, ranking second in terms of per capita per diem availability of milk (835 grams) against the national average of 374 grams (Department of Animal Husbandry and Fishery, 2018-19). Karnal and Jind districts, being in eastern zone, were selected randomly due to high average bovine density, best breeds of animals, high quality feed management, burgeoning dairy sector as well as existence of both organized and unorganized dairy marketing sectors. Two villages from each district were selected randomly for the study.

\section{Collection of data}

A sample of 120 milk producer households was randomly selected for the study. The primary data was collected from the sample households using conventional survey method \&well-structured schedule through personal interview. The data pertaining to socio-economic and demographic particulars of households namely, age, education, family composition, occupation, operational land holding, type of livestock, investment on livestock, machinery and equipments, value of feed, fodder and other miscellaneous expenses, milk production and prices of inputs \& outputs etc. were collected from the sample respondents. The data obtained from the milk producers were post stratified in to small (2-8 milch animals), medium (9-16 milch animals) and large (17-36 milch animals) herd size categories using the cumulative square root frequency technique with milch animal as the basis of classification. Thus, total 120 producer households were classified as 49 small, 55 medium and 16 large herd sized category households.

\section{Analytical framework}

In order to accomplish the objectives of the study, the data collected from the milk producers were scrutinized, tabulated and analyzed utilizing various analytical tool.Tabular analysis was applied to work out the costs and returns from milk production and Garrett ranking approach was followed for identifying the major constraints faced by the farmers during milk production.

\section{Cost of milk production}

The costs and returns of milk production are important indicators of profitable dairy farming. The total costs involved in milk production comprise fixed costs and variable costs. For estimation of different costs and return, the following methodology was followed.

\section{Fixed costs}

Fixed costs $(\mathrm{FC})$ are the expenditure incurred by the producer irrespective of the level of production. They don't vary with the output and remain unchanged in the short-run. Various components of fixed costs include depreciation and interest on fixed capital. Capital Recovery Cost (CRC) method was used for estimation of fixed cost. Another fixed cost item i.e. interest on fixed capital was not estimated separately as CRC approach was followed.

\section{Depreciation cost}

Depreciation is defined as reduction in the value of fixed assets due to wear and tear, over time, accidental damage and technological obsolescence. Annual depreciation on animals, buildings, machinery and equipments used in dairy farming was included for calculation using CRC method.

The formula for estimation of CRC is given by:

$$
R=Z\left[\frac{(1+r)^{n} r}{(1+r)^{n}-1}\right]
$$

Where, $\mathbf{R}$ is the capital recovery cost, $\mathbf{Z}$ is the initial value of the capital asset, $\mathbf{r}$ is the interest rate and $\mathbf{n}$ is the useful life of the assets.

When the assets were purchased from borrowed capital the actual interest rate charged by the bank was taken as ' $r$ ', while in case of owned funds, the rate of interest on term deposit of 1-5 years was taken. The depreciation of milch animals was taken as 10 per cent, 8 per cent and 10 per cent for local cows, crossbred and buffalo with a productive life of $10,12.5$ and 10 years, respectively. The total CRC was then apportioned into individual animal in accordance with Standard Animal Units (SAUs)

\section{Variable Costs}

Variable costs are those costs which are incurred on the variable factors of production. Variable cost items include feed and fodder cost, labour cost, veterinary and miscellaneous expenses. Data on variable expenses were collected from the farmers and annual expenditures were converted to daily expenses. Subsequently, it has been apportioned into standard animal units (SAUs) for standardization followed by comparison.

\section{Feed and fodder cost}

It includes costs of green fodder, dry fodder, concentrates and mineral mixture fed to animals. The cost was estimated as a product of quantity of certain feed/fodder fed to animals and the purchase 
price of respective feed. In case of home grown feed/fodder, their farm harvest prices were considered. Where farm harvest prices were not available, imputed value of crop was taken into account as the prevailing price of standing crop in the locality. For calculating cost of the concentrate feed which was prepared at home, weighted prices of ingredients i.e. share of each component in the concentrate composition was taken into account. When animal feeds were grass and tree leaves collected from common property resources, its imputed value was accounted for estimation of the feed and fodder cost.

\section{Labour cost}

The information regarding labour requirements for various farm operations and labour cost were collected during the personal interview from the farmers. Labour cost comprises both family labour and hired labour. The cost of hired labour was calculated considering type of work allotted and wages paid, whereas, family labour costs were arrived aton the basis of existing wage rate of permanent farm labour.

\section{Veterinary and miscellaneous expenses}

Veterinary expenses included medicines, doctors' fees, vaccination charges as well as natural and artificial insemination charges. Miscellaneous expenditure included electricity, water charges, expenses on repairing fixed assets, and other related expenses.

\section{Standard Animal Units (SAUs)}

Among the various cost items discussed, the producer incurs certain expenses for the entire herd on the farm. Fixed assets like cattle shed, feed manger, chaff cutter, milk cans and buckets etc. are used collectively by the farmer for all the cattle irrespective of their age and sex. Therefore, for assigning the joint expenditures into per animal basis considering the difference in the regional endowments, age of the animals and animal species as these have different effect on cost structure, the entire herd was converted into SAUs following Sirohi et al. (2015) for the northern region. The standard animal unit for the study area i.e. Northern region is given in Table 1.

\section{Other Cost Concepts}

\section{Gross Cost}

It is the total cost incurred by the producer which was estimated by adding all the cost components including fixed and variable costs.

Gross Cost $=$ Total Fixed Cost + Total Variable Cost

Net Cost: The net cost was estimated by deducting the imputed income earned through dung, from the gross cost.
Net Cost $=$ Gross Cost - Value of the Dung

\section{Cost of milk production}

In order to estimate the cost per litre of milk, the net cost per animal per day was divided by average milk of animal per day.

$$
\text { Costperlitreofmilk }(₹ / \text { lit })=\frac{\text { NetCostPerAnimal }}{\text { Avg. Milkyieldofanimal }}
$$

\section{Gross Returns}

Gross returns were obtained by multiplying milk yield of an individual animal with respective prevailing prices in the study area.

Gross Returns: (Milk produced/household /day) * Price of Milk

\section{Net Returns}

Net return was computed by subtracting net cost from gross returns.

Net Returns $=$ Gross Returns - Net Cost

\section{Price of Milk}

The price of milk differs for different type of milk, i.e. buffalo, crossbred cow and local cow milk. Weighted average price of milk was calculated for each household by using the following formula.

$$
\text { Weighted Average Price }=\sum \mathrm{P}_{\mathrm{i}} \mathrm{W}_{\mathrm{i}} / \sum \mathrm{W}_{\mathrm{i}}
$$

Where,

$P_{i}$ is price per litre of the $i^{\text {th }}$ type of milk

$\mathrm{W}_{\mathrm{i}}$ is total quantity of $\mathrm{i}^{\text {th }}$ type of milk sold by the household

\section{Break-even output}

Break-even output (BEO) of milk production indicates the quantity of milk a farmer needs to sell to reach at the break-even pointi.e. point of no profit and no loss. BEO of milk was calculated using the following formula:

$$
\mathrm{BEO}=\mathrm{F} /(\mathrm{P}-\mathrm{V})
$$

Where $\mathrm{F}$ is the total fixed cost for the product, $\mathrm{P}$ is the price per unit of the product and $\mathrm{V}$ is the average variable cost of the product (Venkatesh et al. 2012).

\section{Identification of production constraints}


Garrett's ranking technique is widely used to rank the responses collected through survey (Balaganesh and Kumari, 2017; Sendhil et al. 2013).Based on the primary data collected from the sample households, Garrett's ranking technique was used to analyze the constraints faced by the dairy farmers during milk production system. The constraints identified based on literature review were non-remunerative price of milk, low availability of green fodder, high cost of feed, poor quality of concentrates, distance location of semen collection centres, irregularity in payment, nonavailability of subsidiary feed, lack of quality inputs and high transportation charges in procurement of inputs (Khoveio et al. 2012) The farmers were asked to rank the factors which were identified as limiting factors for livestock production. These orders of merit were transformed into units of scores by using the following formula.

Where,

$$
\text { Percentposition }=\frac{100\left(R_{i j}-0.50\right)}{N_{j}}
$$

$\mathrm{R}_{\mathrm{ij}}$ is the rank for the $\mathrm{i}^{\text {th }}$ factor by the $\mathrm{j}^{\text {th }}$ individual.

$\mathrm{N}_{\mathrm{ij}}$ is the number of factor ranked by the $\mathrm{j}^{\text {th }}$ individual.

The per cent position of each rank was converted into scores by referring to the table given by Garrett and Woodworth (1969). Then for each factor the scores of the individual respondents were added together and divided by the total number of respondents for whom scores were added. These mean scores for all the factors were arranged in descending order and the most influencing factors were identified through the ranks assigned.

\section{Results and Discussion}

Analysis of costs and returns of milk production of different category of milch animal is considered to be an important aspect of dairy enterprise as it reflects the productivity and profitability of the enterprise. The results of the study are presented and discussed as follows.

\section{Costs and returns of milk production from indigenous cows}

The overall gross maintenance cost of indigenous cows was estimated to be Rs. 123.76 per day per cow which varied from ${ }^{1}$ 108.13 per day for small herd size category to Rs 139.46 per day for large size category (Table 2). The overall total fixed cost was estimated to be Rs. 14.78 per day which contributed for about 11.94 per cent of overall gross cost. The overall total variable cost was found to be Rs. 108.98per animal per day which estimated to be Rs. 96.34, Rs. 109.11 and Rs. 121.48 for small, medium and large herd size category, respectively and it accounted for about 88.06 per cent of overall gross cost. From the above table, it is clear that the overall feed and fodder cost constituted a major share for about 76.25 per cent of gross cost,followed by labour cost $(8.35 \%)$. The contribution of feed and fodder cost to the gross maintenance cost was highest as compared to other cost components attributed to the higher price of feed and feed fodder in the study region. The labourers were paid on monthly basis which varied from 8000 to 9000 per month i.e. around 250 to 300 rupees per day. So, when the labour cost was converted into per animal basis it came out to be very low. The dung value was observed to have an increasing trend across the herd size as the large farmers were selling dung to the nearby biogas plants with a reasonable price; while the small farmers were utilizing dung as fuel in the form of dung cake. The contribution of both fixed and variable costs to the gross cost are found to be in conformity with the earlier studies conducted by Singh and Datta (2016).

Overall cost of milk production per litre was estimated at Rs. 31.88. The per litre cost of milk production was found to decrease with increase in the herd size which might be attributed to economies of scale. The net return obtained from per litre milk in case of all the herd size categories was found to be mildly positive. The overall net return per litre of milk was worked out to be Rs. 1.28 and it varied from Rs. 1.79 for large herd size category to Rs. 1.30 for medium and Rs. 0.73 for small size category. The net return from milk production was found to vary positively with the herd size of the households.

Though the net return obtained in the case of indigenous cow was less as compared to crossbred and buffalo in the study area, but the farmers preferred to rear descript indigenous breeds due to their easy adaptability to local climate, low maintenance cost, high fat content but low productivity (Lal and Chandel, 2016). The result obtained regarding the cost and returns of milk production in case of indigenous cows was found to be in conformity with the earlier study conducted by Lal and Chandel (2016) and Athare et al. (2019). The break-even output (BEO) was found to be increasing across the herd size which varied from 3.61 litre per day in case of small herd size to 5.07 litre per day in case of large herd size category. The overall BEO was estimated to be 4.19 litre per day which was higher than the overall productivity of indigenous cow i.e. 3.68 litre per day.

\section{Costs and returns of milk production from crossbred cows}

It can be seen from Table 3 that the overall gross maintenance cost of crossbred cows varied from Rs. 209.47 per day for small herd size category to Rs. 251.44 per day for large herd size category farmers and the overall gross maintenance cost was found to be Rs. 230.16 per day. The overall total fixed cost was estimated to be Rs. 32.08 per day which accounted for about 13.94 per cent of overall gross cost. The overall total variable cost was estimated to be Rs. 198.08 and share of total variable cost in the gross cost was found to be 86.06 per cent. The overall feed and fodder cost constituted a major portion of 71.48 per cent of the gross cost and it varied from Rs. $176.50(70.19 \%)$ per day in case of large herd size category to Rs. $152.00(72.57 \%)$ per day for small herd 
size category. Among the feed and fodder, the concentrates occupied a major share of 29.48 per cent in the gross cost, followed by dry fodder $(25.35 \%)$ and green fodder $(16.64 \%)$. This is due to the higher market price of the concentrates in the study area. The overall labour cost was estimated to be Rs. 24.58 per day with a share of 10.68 per cent to the gross cost and it was found to be highest for large herd size category $(11.16 \%)$ and lowest in case of small herd size category (10.03\%).The results obtained regarding the per cent share of feed cost and labour cost to the gross maintenance cost was found to be on conformity with earlier research conducted by Lal and Chandel (2016), Vanishree et al. (2018) and Athare et al. (2019).
On the perusal of the cost of milk production, the overall cost of production was estimated to be Rs. 32.48 per litre of milk which varied from Rs. 33.37 for small herd size to Rs. 31.87 for the large herd size category. The cost of milk production was observed to be higher in crossbred cows as compared to indigenous cows due to the higher expenses on feed and fodder in case of crossbred cow. The per litre cost of milk production was found to vary negatively with the herd size. Hence, lowest cost of milk production per litre of milk was estimated in case of largeherd size and highest in case of smallherd size category due to the economics of scale in dairying. The result regarding the per litre cost of milk production was in accordance with earlier studies conducted by Lal and Chandel (2016) and Acharya and Malhotra (2020).

Table 1 Standard animal units for Northern region of India

\begin{tabular}{llll}
\hline Animals & Indigenous cow & Crossbred cow & Buffalo \\
\hline Adult male $(\geq 3$ years $)$ & 1.08 & 1.23 & 1.25 \\
Adult female $(\leq 3$ years $)$ & 1.00 & 1.27 & 1.35 \\
Young stock male $(<1$ year $)$ & 0.39 & 0.41 & 0.43 \\
Young stock female $(<1$ year $)$ & 0.39 & 0.41 & 0.41 \\
Young stock male $(>1$ year $)$ & 0.54 & 0.61 & 0.65 \\
Young stock female $(>1$ year $)$ & 0.46 & 0.52 & 0.51 \\
Heifer & 0.73 & 0.78 & 0.79 \\
\hline
\end{tabular}

Table 2 Costs and returns of milk production of indigenous cows (Rs./animal/day)

\begin{tabular}{|c|c|c|c|c|}
\hline \multirow[t]{2}{*}{ Cost/Returns components } & \multicolumn{3}{|c|}{ Herd size category } & \multirow[t]{2}{*}{ Overall } \\
\hline & Small & Medium & Large & \\
\hline Total Fixed Cost (TFC) & $11.79(10.90)$ & $14.58(11.79)$ & $17.98(12.89)$ & $14.78(11.94)$ \\
\hline Green fodder (F1) & $22.08(20.42)$ & $25.71(20.79)$ & $26.04(18.67)$ & $24.61(19.89)$ \\
\hline Dry fodder (F2) & $21.97(20.32)$ & $23.64 \quad(19.11)$ & $27.14(19.46)$ & $24.25(19.59)$ \\
\hline Concentrate (F3) & $42.39(39.21)$ & $45.34 \quad(36.66)$ & $48.79(34.99)$ & $45.51(36.77)$ \\
\hline $\begin{array}{l}\text { Feed and fodder cost } \\
(\mathrm{V} 1=\mathrm{F} 1+\mathrm{F} 2+\mathrm{F} 3)\end{array}$ & $86.45(79.95)$ & $94.69 \quad(76.55)$ & $101.97(73.12)$ & $94.37(76.25)$ \\
\hline Labour cost (V2) & $5.89 \quad(5.45)$ & $(8.32)$ & $14.82(10.63)$ & $10.33(8.35)$ \\
\hline Veterinary \& Miscellaneous cost (V3) & $4.00 \quad(3.70)$ & $4.13 \quad(3.34)$ & $4.69 \quad(3.36)$ & $4.28 \quad(3.46)$ \\
\hline $\begin{array}{l}\text { Total Variable Cost } \\
(\mathrm{TVC}=\mathrm{V} 1+\mathrm{V} 2+\mathrm{V} 3)\end{array}$ & $96.34(89.10)$ & $109.11(88.21)$ & $121.48(87.11)$ & $108.98(88.06)$ \\
\hline Gross $\operatorname{Cost}(\mathrm{A}=\mathrm{TFC}+\mathrm{TVC})$ & $108.13(100.00)$ & $123.70(100.00)$ & $139.46(100.00)$ & $123.76(100.00)$ \\
\hline Value of Dung (B) & 3.58 & 5.48 & 10.83 & 6.63 \\
\hline $\operatorname{Net} \operatorname{Cost}(C=A-B)$ & 104.55 & 118.22 & 128.62 & 117.13 \\
\hline Price of milk (Rs. /litre) & 32.98 & 33.18 & 33.30 & 33.15 \\
\hline $\begin{array}{l}\text { Average milk productivity } \\
\text { (litre/animal/day) (E) }\end{array}$ & 3.24 & 3.71 & 4.08 & 3.68 \\
\hline Gross Return (D) & 106.92 & 123.05 & 135.95 & 121.97 \\
\hline Net Returns (D-C) & 2.37 & 4.83 & 7.33 & 4.84 \\
\hline Cost of milk production (Rs /litre) (C/E) & 32.25 & 31.88 & 31.50 & 31.88 \\
\hline Net Returns (Rs. /litre) (D/E) & 0.73 & 1.30 & 1.79 & 1.28 \\
\hline Average Variable Cost $(\mathrm{AVC}=\mathrm{TVC} / \mathrm{E})$ & 29.72 & 29.42 & 29.75 & 29.63 \\
\hline Break even output (lit) ( TFC/ Price-AVC) & 3.61 & 3.87 & 5.07 & 4.19 \\
\hline
\end{tabular}

Figures in parentheses indicate the percentage of gross cost 
The overall net return was estimated to be Rs.3.29 per litre of milk and it was found to be positive for all the categories of households. The net return per litre of milk was worked out to be Rs. 2.01, Rs.3.70 and Rs. 4.17 in case of small, medium and large herd size categories, respectively and the net returns from all the three categories of households were found to be varying positively with the herd size. Crossbred milk was basically sold to the milk vendors and dairy processing plants attributed to the higher price of crossbred milk as compared to the milk of indigenous cows which was mostly sold in the neighborhoods. Highest net return obtained in case of large herd size followed by medium and small herd size categories. The result obtained regarding the cost of production and net return per litre of milk was found to be similar with the study conducted by Kumari et al. (2016), Vanishree et al. (2018), Athare et al. (2019) and Acharya and Malhotra (2020). The overall yield obtained in case of crossbred cow was worked out to be 6.82 litre per day which was found to be much higher than the break-even output i.e. 4.76 litre per day.

\section{Costs and returns of milk production of buffalos}

The cost and return of milk production of buffalo is presented in Table 4. The overall gross cost for buffalo milk production was estimated at Rs. 226.58 per day which varied from Rs. 203.89 in case of small herd size to Rs. 247.26 for large herd size category. The overall total fixed cost and total variable cost for milch buffalo was computed at Rs. 34.79 and Rs. 191.78 per day, respectively.

The share of total fixed cost and total variable cost to the overall gross maintenance cost was found to be 15.36 per cent and 84.64 per cent, respectively. The result obtained was in conformity with earlier studies conducted by Vanishree et al. (2018), Athare et al. (2019) and Acharya and Malhotra (2020). The contribution of overall feed and fodder cost to the gross cost was found to be 70.71 per cent, followed by overall labour cost (9.68\%). Among the feed and fodder, the contribution of overall green fodder, dry fodder and concentrates to the gross cost was worked out to be 17.34 per cent, 24.79 per cent and 28.57 per cent, respectively. Highest cost share of concentrates was attributed to their high cost and lowest share of green fodders was due to their high productivity in the study area. Higher cost of production in case of buffaloes was the result of their higher quantity of feed intake as compared to indigenous and crossbred cows.

The overall cost of production per litre of milk was estimated to be Rs.40.35. The net return per litre of milk production was positive for all the herd size categories. The net return was found to be Rs. 1.82 , Rs. 3.48 and Rs. 4.06 per litre of milk for small, medium and large herd size categories, respectively. The overall net return per litre of milk was worked out to be Rs. 3.12 which was lower

Table 3 Costs and returns of milk production of crossbred cows (Rs. /animal/day)

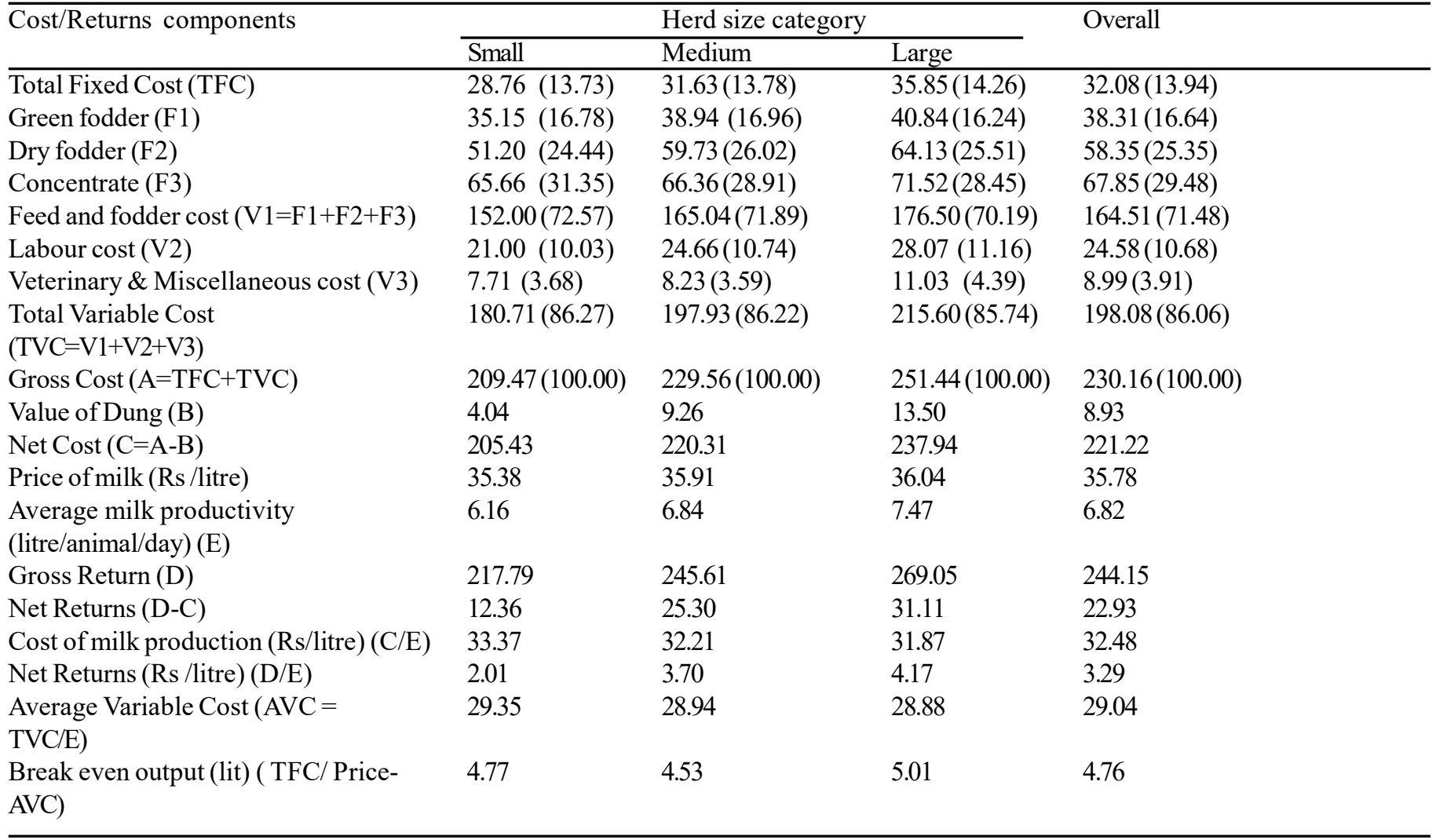

Figures in parentheses indicate the percentage of gross cost 
Table 4 Costs and returns of milk production of buffalos (Rs. /animal/day)

\begin{tabular}{|c|c|c|c|c|}
\hline \multirow[t]{2}{*}{ Cost/Returns components } & \multicolumn{3}{|c|}{ Herd size category } & \multirow[t]{2}{*}{ Overall } \\
\hline & Small & Medium & Large & \\
\hline Total Fixed Cost (TFC) & $31.39(15.40)$ & $34.11 \quad(14.92)$ & $38.88(15.72)$ & $34.79(15.36)$ \\
\hline Green fodder (F1) & $36.81(18.05)$ & $39.35 \quad(17.22)$ & $41.73(16.88)$ & $39.30(17.34)$ \\
\hline Dry fodder (F2) & $50.52(24.78)$ & $57.19 \quad(25.02)$ & $60.78(24.58)$ & $56.16(24.79)$ \\
\hline Concentrate (F3) & $61.11(29.97)$ & $65.23 \quad(28.54)$ & $67.89(27.46)$ & $64.74(28.57)$ \\
\hline Feed and fodder cost $(\mathrm{V} 1=\mathrm{F} 1+\mathrm{F} 2+\mathrm{F} 3)$ & $148.45(72.81)$ & $161.78(70.77)$ & $170.39(68.91)$ & $160.21(70.71)$ \\
\hline labour cost (V2) & $17.10 \quad(8.39)$ & 23.43 a $(10.25)$ & $25.27(10.22)$ & $21.93(9.68)$ \\
\hline Veterinary \& Miscellaneous cost (V3) & $6.96 \quad(3.41)$ & $(4.05)$ & $12.73(5.15)$ & $9.65(4.26)$ \\
\hline Total Variable Cost $(\mathrm{TVC}=\mathrm{V} 1+\mathrm{V} 2+\mathrm{V} 3)$ & $172.50(84.60)$ & $194.47(85.08)$ & $208.38(84.28)$ & 191.78 (84.64) \\
\hline Gross Cost $(\mathrm{A}=\mathrm{TFC}+\mathrm{TVC})$ & $203.89(100.00)$ & $228.58(100.00)$ & $247.26(100.00)$ & $226.58(100.00)$ \\
\hline Value of Dung (B) & 6.03 & 11.18 & 15.80 & 11.00 \\
\hline $\operatorname{Net} \operatorname{Cost}(\mathrm{C}=\mathrm{A}-\mathrm{B})$ & 197.86 & 217.40 & 231.47 & 215.58 \\
\hline Price of milk (Rs. /litre) & 42.99 & 43.58 & 43.84 & 43.47 \\
\hline $\begin{array}{l}\text { Average milk productivity } \\
\text { (litre/animal/day) (E) }\end{array}$ & 4.81 & 5.42 & 5.82 & 5.35 \\
\hline Gross Return (D) & 206.58 & 236.28 & 255.08 & 232.65 \\
\hline Net Returns (D-C) & 8.73 & 18.87 & 23.61 & 17.07 \\
\hline Cost of milk production (Rs. /litre) (C/E) & 41.17 & 40.10 & 39.79 & 40.35 \\
\hline Returns (Rs. /litre) (D/E) & 1.82 & 3.48 & 4.06 & 3.12 \\
\hline Average Variable Cost $(\mathrm{AVC}=\mathrm{TVC} / \mathrm{E})$ & 35.89 & 35.87 & 35.82 & 35.86 \\
\hline Break even output (lit) ( TFC/ Price-AVC) & 4.41 & 4.42 & 4.84 & 4.57 \\
\hline
\end{tabular}

Figures in parentheses indicate the percentage of gross cost

than the overall net return of crossbred cow (Rs. 3.29) in spite of higher marker price of the buffalo milk due to high fat content. It could be due to the lower average productivity of buffalo (5.35lit/ animal/day) than the crossbred cows (6.82 lit/animal/day). The low productivity in case of buffaloes was due to poor management practices as well as less accessible veterinary and Artificial Insemination (AI) practices in the study region. The result obtained in respect of the cost of milk production and net return was found to be comparable with the earlier studies conducted by Lal and Chandel (2016) and Kumari et al. (2016). The breakeven output in case of buffalo varied from 4.41 litre per day for small herd size to 4.87 litre per day for large herd size category. The overall productivity of buffalo was found to be higher than the overall break even output i.e. 4.57 litre per day.

The constraints faced by the dairy farmers in milk production are presented in Table 5. It can be seen that distance location of semen collection centres and high price of concentrates were found to be the major constraints in milk production faced by the farmers with a Garrett mean score of 73.29 and 71.23 , respectively. Khoveio et al. (2012) also reported that the low availability of feeds and high market prices of concentrates were the major production constraints in milk production. Poor quality of concentrates and non-availability of subsidized feed were also identified as some of the major constraints faced by the farmers. However, factors like lack of veterinary facilities, high transportation charges and non-remunerative prices of milk were found to be of least importance. Low availability of green fodder was found to be least important with Garrett mean score of 24.94 due to high fodder yield and availability of green fodders like berseem, cowpea, fodder maize etc. in the study area.

\section{Conclusions}

In the present study on economic analysis of milk production, it was found that the overall cost of milk production decreased as the herd size increased, while the overall net returns per litre of milk increased with the herd size. It was highest for crossbred cows (Rs. 3.29) followed by buffalo (Rs.3.12) and indigenous cows (Rs.1.28). It can be concluded that the crossbred cows are economically beneficial for the dairy farmers as their overall per day yield was found to be much higher than the overall breakeven output (BEO). However, efforts must be taken to improve the productivity of indigenous cattle by means of proper training programs and facilitation of scientific rearing practices. Moreover, it was also seen that in case of all the animal categories, the net returns varied positively with the herd size. Therefore, it can be concluded that due to rearing of better breeds, adoption of better feeding and management practices, the farmers having large herd size of animals were more benefitted than their counterparts. Hence, efforts should be taken to bridge the knowledge gap of especially small and medium farmers and enabling them to adopt 
better rearing practices to obtain higher milk yield and net returns from dairy farming. The study also observed that distant location of semen collection centres and high price of concentrates were the major production constraints faced by the farmers. Steps should be taken to establish new semen collection centres with easy accessibility for the farmers or deliver the quality semen at doorsteps by mobile van as well as making availability of concentrates at subsidized price to the milk producers which can be channelized through Farmer Producer Organizations (FPOs).

\section{References}

Garrett HE, Woodworth RS (1969) Statistics in Psychology and Education, Vakils, Feffer and Simons Pvt. Ltd. Bombay, pp. 329

Khoveio M, Jain DK, Chauhan AK (2012) Economics of milk production and its constraints in Nagaland. Indian J Dairy Sci 65: 520-526

Venkatesh P, Sangeetha V, Sundaramoorthy C, Sendhil R, Thomas L (2012) A study on economics of milk products in Madurai district of Tamilnadu. Bioinfolet 9: 298

Sendhil R, Kar A, Mathur VC, Jha G K, Singh R (2013) Is wheat futures market relevant to small scale production system in India? Indian $\mathrm{J}$ Agric Marketing 27: 31-38

Sirohi S, Bardhan D, Chand P (2015) Cost and return in milk production: Developing standardised methodology and estimates for various production systems, Project Report of ICAR- National Dairy Research Institute (Deemed University), Karnal submitted to Department of Animal Husbandry, Dairying and Fishery, Ministry of Agriculture and Farmers Welfare, New Delhi

Singh P, Datta KK (2016) Economic analysis of traditional milk supply chain in Ranchi district of Jharkhand. Indian J Econ Dev 12: $495-$ 502
Kumari B, Malhotra R, Chauhan AK (2016) Impact of woman dairy cooperatives on economics of milk production in Begusarai District of Bihar. Indian J Dairy Sci 69:487-491

Lal P, Chandel B S (2016) Economics of milk production and cost elasticity analysis in Sirsa district of Haryana. Econ Affairs 61: 405-411

Balaganesh G, Kumari B (2017) Ranking of Responses: Garrett's Approach. In eds. Sendhil R, Kumar A, Singh S, Verma A, Venkatesh K. Vikas G. Data Analysis Tools and Approaches (DATA) in Agricultural Sciences, ICAR-Indian Institute of Wheat and Barley Research, Karnal. pp 126. ISBN: 978-93-5300-510-8. DOI: 10.13140/ RG.2.2.28187.57125

Vanishree M, Sendhil R, Sirohi S, Chauhan A K, Rashmi H M, Ponnusamy K (2018) Value chain analysis of input delivery system for liquid milk in Bengaluru milk union of Karnataka. Indian J Dairy Sci 71: 502-508

Athare P G, Verma A, Malhotra R, Sendhil R (2019) Economics of milk production in Pune district of Maharashtra: A comparative analysis. Indian J Dairy Sci 72: 652-658

Acharya K K, Malhotra R (2020) Economic analysis of milk production in peri-urban dairy farms of Odisha. Indian J Dairy Sci 73: 155-159 